\title{
Drawing with the Non-dominant Hand: Implications for the Study of Construction
}

\author{
Sherma Zacharias and Andrew Kirk
}

\begin{abstract}
Background: Constructional impairment following left vs. right hemisphere damage has been extensively studied using drawing tasks. A confounding factor in these studies is that right-handed patients with left hemisphere damage (LHD) are often forced by weakness to use their non-dominant (left) hand or hemiparetic dominant hand. Qualitative differences in the drawing characteristics of left and right hand drawings by normal subjects have not previously been characterized. The present study was undertaken to determine the qualitative differences between left and right hand drawings of normal subjects. Methods: Thirty right-handed, elderly subjects without a history of neurological disease were asked to draw, from memory, seven objects using the right and left hand. Half of the subjects were randomly assigned to draw with the left hand first, and half the right hand first. Right and left hand drawings were compared using a standardized scoring system utilized in several previous studies of drawing in focal and diffuse neurological disease. Each drawing was scored on eighteen criteria. Right and left hand drawing scores were then compared using the t-test for paired samples or the Wilcoxon matched-pairs test. Results: Drawings made using the left hand were found to be significantly simpler, more tremulous and of poorer overall quality than drawings made by the same subjects using the right hand. Conclusions: The deficits found in left versus right hand drawings of normals are similar to those found in patients with LHD, suggesting that much of the drawing impairment seen following LHD is due to an elementary motor disturbance related to use of the non-dominant hand.
\end{abstract}

\begin{abstract}
RÉSUMÉ: Le dessin avec la main non dominante: implications pour l'étude de la construction. Introduction: L'altération de la capacité de construction suite à une lésion de l'hémisphère gauche vs. droit a été étudiée de façon approfondie au moyen du dessin. Un facteur confondant dans ces études vient du fait que les droitiers ayant une lésion à l'hémisphère gauche (LHG) sont souvent forcés d'utiliser leur main non dominante (gauche) à cause de la faiblesse ou leur main dominante hémiparétique. Les différences qualitatives dans les caractéristiques des dessins exécutés avec la main gauche et la main droite de sujets normaux n'ont jamais été caractérisées. La présente étude a été entreprise pour déterminer les différences qualitatives entre les dessins exécutés de la main gauche et de la droite par des sujets normaux. Méthodes: On a demandé à trente sujets droitiers âgés, sans histoire de maladie neurologique, de dessiner de mémoire sept objets avec leur main droite et leur main gauche. On a demandé au hasard à la moitié des sujets de dessiner d'abord avec leur main gauche et à l'autre moitié de dessiner d'abord avec leur main droite. Nous avons comparé les dessins exécutés avec la main droite et la main gauche au moyen d'un système de pointage standardisé utilisé dans plusieurs études antérieures sur le dessin dans la maladie neurologique focale et diffuse. Chaque dessin recevait un pointage sur dix-huit critères. Les pointages pour les dessins exécutés avec la main droite et la main gauche ont été ensuite comparés au moyen d'un test de " $t$ " pour les échantillons pairés ou du test de Wilcoxon pour les observations appariées. Résultats: Les dessins faits avec la main gauche étaient significativement plus simples, plus tremblotants et en général de moindre qualité que les dessins faits par le même sujet avec la main droite. Conclusions: Les déficits observés dans les dessins exécutés par des sujets normaux avec la main gauche par rapport à ceux exécutés avec la main droite sont semblables à ceux observés dans les dessins des patients ayant une LHG, ce qui suggère qu'une grande partie du déficit dans le dessin observé suite à une LHG est dû à un dérangement moteur élémentaire relié à l'utilisation de la main non dominante.
\end{abstract}

Can. J. Neurol. Sci. 1998; 25: 306-309

Constructional impairment is commonly an outcome following a cerebral insult. ${ }^{1}$ Early studies identified constructional impairment as a left hemisphere deficit due to its frequent association with Gerstmann syndrome. ${ }^{2}$ Subsequent studies, however, have reported constructional impairment following damage to either hemisphere. ${ }^{3-7}$

Duensing, ${ }^{8}$ in 1953 , noted that patients with left hemisphere damage (LHD) produced drawings that were simplified and hesitant, whereas patients with right hemisphere damage (RHD) had more difficulty reproducing the correct spatial relationships between parts of their drawings. Based on these observations, he suggested that right hemisphere lesions affect construction by causing a visuo-perceptual impairment, whereas left hemisphere lesions produce an executive deficit. Subsequent studies examining this phenomenon have further reported that patients with

From the Division of Neurology, University of Saskatchewan, Saskatoon, Saskatchewan.

RECEIVED MARCH 16, 1998. ACCEPTED IN FINAL, FORM JUNE 23, 1998

Reprint requests to: Andrew Kirk, Division of Neurology, Royal University Hospital, 103 Hospital Drive, Saskatoon, Saskatchewan, Canada S7N 0W8 
LHD produce simple, tremulous drawings containing fewer angles and details. ${ }^{3,6,7,9,10}$ Patients with RHD, on the other hand, produce relatively complex drawings that may be spatially incorrect and often display hemispatial neglect., ${ }^{3,6,11,12}$

It has been suggested that much of the drawing impairment exhibited by (right-handed) patients suffering LHD may be due to use of a hemiparetic right hand, or nondominant left hand. .,13 $^{2}$ In particular, it has been noted that severity of hemiparesis is a better predictor of drawing impairment than are lesion size and location in patients with LHD. ${ }^{6}$ Although some authors have mentioned in passing that a number of patients with right hemiparesis (due to LHD) were forced to use their left hand for drawing, ${ }^{14,15}$ it is only recently that this possibility has been explored in an attempt to explain the drawing errors made by patients with LHD. $6,7,13,16$

Surprisingly few studies have examined the characteristics of drawings made by normal subjects using their non-dominant hand. An early study by Dee and Fontenot ${ }^{17}$ compared drawings made with the left and right hand of (right-handed) non-neurological subjects. They found that drawing performance was not significantly affected by use of the non-dominant left hand. These results, however, only show that the Visual Retention Test ${ }^{18}$ scored on a small number of criteria, does not differentiate drawings made with the dominant and non-dominant hand. Intuitively, one would expect that use of the non-dominant hand would result in drawings of poor overall quality. The ability to specifically characterize the drawing errors made by subjects using the nondominant hand is important as it may allow low level motor errors (due to hemiparesis or use of the non-dominant hand) to be disentangled from cognitively-based errors made following LHD.

A standardized rating system, previously used to study drawing impairment following neurological damage ${ }^{6,7,19-21}$ was used to compare drawings made by normal elderly subjects using their left and right hand, in order to determine the types of qualitative differences that exist under these two conditions.

\section{METHODS}

Subjects. Thirty healthy right-handed volunteers were included. Subjects had no previous history of neurological symptoms, arthritis or any other medical problems which might affect drawing ability. Thirteen subjects were male. The mean age of the subjects was 69.9 (standard deviation 7.9) years. The mean educational level was 12.5 (standard deviation 2.9) years.

Procedure. The Western Aphasia Battery (WAB) ${ }^{22}$ drawing subtest was administered to each subject by asking them to spontaneously draw (without being shown a model) a circle, cube, square, clock, tree, house and person. After drawing all seven objects, each subject was asked to draw these objects again using the opposite hand. The hand used first for drawing the seven objects was determined by random assignment, with half of the subjects drawing with the left hand first, and half drawing with the right hand first.

Each set of drawings received a random subject number. All other identifying data were masked. Drawings were individually scored using the criteria shown in Table 1. Because previous studies, using the same rating scale, reported high inter-rater reliability, $6,7,19-21$ only one rater (the first author) was used in the present study. For each item in Table 1 the rater, who was blinded as to whether a set of drawings was done with the left or right hand, assigned scores for the seven individual drawings. The scores for the individual drawings were then added to give a series of total item scores for each subject. Scores for the left and right hand drawings were then compared. The t-test for paired samples was used to compare counted items (e.g., internal details), whereas the Wilcoxon matched-pairs test was used for rated items (e.g., orientation). Because multiple comparisons were performed, $p<.002$ was used to denote significance.

Table 1: Criteria Used to Rate Drawings.*

\section{Items rated on $0-3$ scale}

\section{Scale}

0 - Normal

1 - Mildly abnormal

2 - Moderately abnormal

3- Severely abnormal

\section{Spatial relationships}

Tendency for components of drawings to be put together abnormally with respect to one another in a piecemeal fashion, so that the whole picture is distorted, resembling an "exploded diagram"

\section{Simplification}

Tendency to oversimplify the drawing, leaving out details

\section{Angle production}

Difficulty forming angles with a tendency to represent them as gaps, scrawls or curved lines (circle not rated)

\section{Perseveration}

Tendency to redraw lines, parts of the drawing, or the entire drawing

\section{Tremulousness}

Tendency for lines to be shaky

\section{Perspective}

Tendency for three-dimensional perspective to be poorly represented (only cube and house rated)

$\frac{\text { Overall impairment }}{\text { Rating of each drawing as a whole }}$
Items rated on -3 to +3 scale

Scoring system as above but with negative numbers indicating leftward error and positive rightward error

\section{Orientation}

Tendency for drawings to be placed diagonally on the page. Sign indicates the side away from which the drawing leans (circle not rated)

\begin{tabular}{l} 
Neglect \\
$\begin{array}{l}\text { Tendency for one side of the drawing to be incomplete or } \\
\text { underdeveloped }\end{array}$ \\
\hline Displacement \\
\hline $\begin{array}{l}\text { Tendency for drawings to be displaced toward one side of the page } \\
\text { (single rating for all drawings) }\end{array}$ \\
\hline
\end{tabular}

\begin{tabular}{ll}
\hline & Items counted \\
\hline Details & \\
\hline
\end{tabular}

Total number of details included (e.g., numbers, hands, windows, facial features) 


\section{Details externalized}

Number of details incorrectly placed outside rather than inside the outline of the drawing (circle and square not rated)

\section{Angles}

Total number of angles drawn and percent acute, right and obtuse (clock, tree and person not rated)

\section{Redrawn lines}

Number of lines that have been overdrawn at least once

\section{Line production}

Total number of lines drawn (only circle, square and cube rated)

\begin{tabular}{l} 
Line joining \\
Number of gaps separating lines that should meet \\
\hline Line crossing
\end{tabular}

Line crossing

Number of crossings of lines that should just meet

\section{Item measured}

Area

Maximum vertical height of drawing multiplied by maximum horizontal width (in $\mathrm{cm}^{2}$ ) (area of seven drawings summed).

*After Kirk and Kertesz ${ }^{6}$

\section{Results}

Drawing scores are summarized in Table 2. Significant differences between use of the left and right hand for drawing included orientation, simplification, tremulousness, and overall quality

Table 2: Mean Drawing Scores of Subjects Using the Right and Left Hand.

\begin{tabular}{|c|c|c|c|c|c|}
\hline \multirow[b]{2}{*}{ Spatial Relationships } & \multicolumn{2}{|c|}{$\begin{array}{l}\text { Left-handed scores } \\
\text { (SD) }(\mathbf{N}=\mathbf{3 0})\end{array}$} & \multicolumn{3}{|c|}{$\begin{array}{l}\text { Right-handed scores } \\
\text { (SD) }(\mathbf{N}=\mathbf{3 0})\end{array}$} \\
\hline & 0.00 & $(0.00)$ & 0.00 & $(0.00)$ & \\
\hline Simplification & 3.10 & $(2.56)$ & 2.00 & $(2.23)$ & $(\mathrm{p}=.0006)$ \\
\hline Angle production & 0.23 & $(0.63)$ & 0.00 & $(0.00)$ & \\
\hline Perseveration & 0.07 & $(0.25)$ & 0.13 & $(0.35)$ & \\
\hline Tremulousness & 4.57 & (3.98) & 0.37 & $(0.61)$ & $(\mathrm{p}<.00005)$ \\
\hline Perspective & 1.57 & (1.94) & 1.57 & $(1.89)$ & \\
\hline Orientation & -0.47 & (2.13) & 2.57 & (1.98) & $(\mathrm{P}<.00005)$ \\
\hline Neglect & 0.00 & $(0.00)$ & 0.00 & $(0.00)$ & \\
\hline Displacement & -1.17 & $(1.32)$ & -0.70 & $(1.60)$ & \\
\hline Details & 42.57 & $(18.84)$ & 50.0 & $(25.27)$ & \\
\hline Details externalized & 0.40 & $(2.19)$ & 0.60 & $(3.29)$ & \\
\hline Right angles (\%) & 10.07 & $(8.51)$ & 8.65 & $(7.34)$ & \\
\hline Acute angles (\%) & 46.90 & $(5.16)$ & 45.19 & $(6.89)$ & \\
\hline Obtuse angles (\%) & 44.01 & $(6.53)$ & 46.23 & $(6.41)$ & \\
\hline Total angles & 42.00 & (11.11) & 44.87 & $(11.98)$ & \\
\hline Redrawn lines & 1.33 & $(1.77)$ & 1.40 & $(2.74)$ & \\
\hline Line production & 12.87 & $(2.40)$ & 13.57 & $(1.74)$ & \\
\hline Line joining & 29.20 & $(12.09)$ & 40.43 & $(29.16)$ & \\
\hline Line crossing & 16.17 & $(6.22)$ & 15.73 & $(7.28)$ & \\
\hline Area $\left(\mathrm{cm}^{2}\right)$ & 269.26 & $(158.14)$ & 259.12 & (159.18) & \\
\hline Overall impairment & 3.07 & $(2.49)$ & 1.57 & $(1.89)$ & $(\mathrm{P}=.00002)$ \\
\hline
\end{tabular}

These results indicate that subjects drawing with the left hand tended to orient their drawings diagonally on the page, with the left side higher than the right. Additionally, when subjects were asked to use their left hand the drawings tended to be simplified, with a tendency to leave out details. The left-handed drawings were also more tremulous than the right-handed drawings. Finally, the rating for overall quality was also worse for left- as compared to right-handed drawings. Samples of right and left handed drawings are shown in Figures 1 and 2.
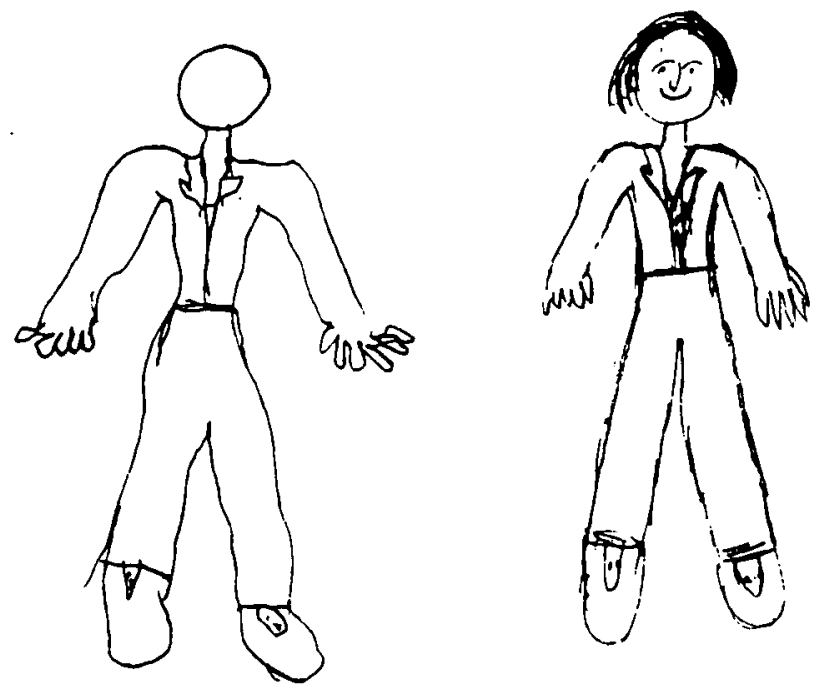

Figure 1: Drawings made by a 71-year-old woman using the left (person on left side of page) and right (person on right side of page) hand.
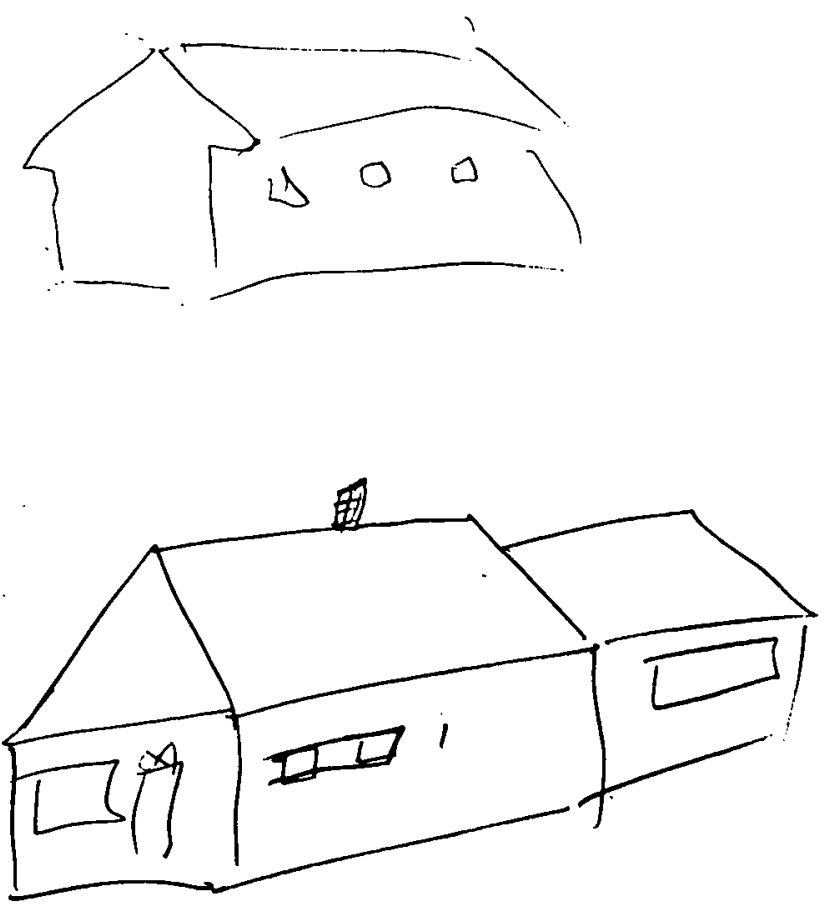

Figure 2: Drawings of a house made by a 70-year-old man using his right (bottom picture) and left (top picture) hand. 


\section{Discussion}

The main finding of this study was that left-handed drawings were simplified, tremulous and of poorer overall quality. These deficits are similar to many of those reported in previous studies of patients with LHD. In particular, it has previously been found that (right-handed) patients with left cerebral strokes forced to use their left hand (due to hemiparesis) for drawing made more simplification errors and showed an overall drawing impairment compared to similar patients who were able to use their right hand. ${ }^{7,13,16}$ Kirk \& Kertesz ${ }^{7}$ specifically reported the left-handed drawings of LHD patients to be more tremulous. This evidence, along with the finding that severity of hemiparesis was significantly correlated with drawing quality, led to the proposal that a low-level motor deficit may be the source of these drawing errors. ${ }^{6,7}$ The present finding that left-handed drawing resulted in a tendency to orient drawings diagonally with the left side higher than the right may be related to orientation of the paper by normal subjects during drawing. This has not been a characteristic finding in LHD patients.

The findings from the present study support the hypothesis that a number of the drawing errors made by patients following LHD are indeed the result of a motor deficit involving use of the non-dominant hand due to right-sided hemiparesis. It is also important to note, however, that not all of the drawing errors previously reported following LHD can be attributed to a pure motor deficit. In fact, Warrington, James, and Kinsbourne ${ }^{23}$ additionally reported that LHD patients included fewer details, widened the angles and produced more right angles than patients with RHD. Kirk and Kertesz ${ }^{6,7}$ found that the drawings of right vs. left hemisphere damaged patients also differed in degree of displacement on the page, number of internal details, quality of angle production and total line production. A confounding factor in these previous studies is that patients with LHD forced to use their left hand may have had larger lesions than those patients able to draw with the right hand.

The presence of these differences in normal subjects suggests that drawing tasks may allow one to distinguish between low level motor deficits and underlying cognitive deficits following LHD. Separating these two factors is important in distinguishing between the deficits in constructional impairment seen following right- vs. left-hemisphere damage. In particular, the production of simplified, tremulous drawings following LHD is consistent with use of the left hand in normals and does not, therefore, appear to be the result of a specific non-motor constructional impairment. Many of the drawing errors described in previous studies were not found in the present study, suggesting that LHD does produce an impairment in drawing that is not purely motor in nature. In particular, displacement on the page, number of internal details, quality of angle production, and total line production are other factors that characterize LHD drawings but are not seen in normals drawing with the left hand. It has been suggested that, in addition to a low level motor deficit, patients suffering LHD also experience an abnormality in concept formation, thereby producing simplified drawings. ${ }^{6,24}$ Our results, however, do not support this hypothesis as an explanation for the production of simplified drawings following LHD, as normal subjects drawing with the left hand also produce simplified drawings.

In conclusion, the results reported here indicate that use of the left (non-dominant) hand for drawing does influence certain performance characteristics. In particular, our results suggest that use of the non-dominant hand due to hemiparesis is an important contributor to the drawing impairment seen following LHD. Similarly, it seems likely that a residual dominant hand weakness following LHD could also result in the production of simplified, tremulous drawings.

\section{REFERENCES}

1. Kirk A, Kertesz A. Localization of lesions in constructional impairment. In: Localization and Neuroimaging in Neuropsychology. San Diego: Academic Press, 1994; 525-544.

2. Benson DG, Barton MI. Disturbances in constructional ability. Cortex $1970 ; 6: 19-46$.

3. Arrigoni G, De Renzi E. Constructional apraxia and hemispheric locus of lesion. Cortex 1964; 1: 170-197.

4. Benton AL. Constructional apraxia and the minor hemisphere. Confin Neurol 1967; 27: 1-17.

5. Benton AL, Fogel ML. Three dimensional constructional praxis. Arch Neurol 1962; 7: 347-354.

6. Kirk A, Kertesz A. Hemispheric contributions to drawing. Neuropsychologia 1989; 27: 881-886.

7. Kirk A, Kertesz A. Subcortical contributions to drawing. Brain and Cognition 1993; 21: 57-70.

8. Duensing F. Raumagnostische und ideatorisch-apraktische Störung des gestaltenden Handelns. Deutsche Zeitschrift fuer Nervenheilkunde 1953; 170: 72-94.

9. McFie J, Zangwill OL. Visual-constructive disabilities associated with lesions of the left cerebral hemisphere. Brain 1960; 82: 243-259.

10. Piercy $M$, Hécaen $H$, Ajuriaguerra J. Constructional apraxia associated with unilateral cerebral lesions-left and right sided cases compared. Brain 1960; 85: 775-789.

11. Patterson A, Zangwill OL. Disorders of visual space perception associated with lesions of the right cerebral hemisphere. Brain 1944; 67: 331-358.

12. McFie J, Piercy MF, Zangwill OL. Visual spatial agnosia associated with lesions of the right cerebral hemisphere. Brain 1950; 73: 167-190.

13. Archibald YM. Simplification in the drawings of left hemisphere patients - a function of motor control? Paper presented at the meeting of the Academy of Aphasia; 1978; Chicago.

14. Gainotti G, Tiacci C. Patterns of drawing disability in right and left hemispheric patients. Neuropsychologia 1970; 8: 379-384.

15. Hécaen H, Assal G. A comparison of constructive deficits following right and left hemispheric lesions. Neuropsychologia 1970; 8: 289-303.

16. Carlesimo GA, Fadda L, Caltagirone C. Basic mechanisms of constructional apraxia in unilateral brain-damaged patients: role of visuo-perceptual and executive disorders. J Clin Exp Neuropsychol 1993; 15(2): 342-358.

17. Dee HL, Fontenot DJ. Use of the non-preferred hand in graphomotor performance: a methodological study. Confin Neurol 1969; 31: 273-280.

18. Benton AL. The visual retention test as a constructional praxis task. Confin Neurol 1962; 22: 1-16.

19. Kirk A, Kertesz A. On drawing impairment in Alzheimer's disease. Arch Neurol 1991; 48: 73-77.

20. Kirk A, Kertesz A. Recovery from drawing impairment after hemispheric stroke. Paper presented at the twentieth annual meeting of the International Neuropsychological Society; February 7, 1992; San Diego.

21. Kirk A, Rajput AH. On drawing impairment in Parkinson's disease with and without dementia. Can J Neurol Sci 1994; 21: S27.

22. Kertesz A. The Western Aphasia Battery. New York: Grune \& Stratton, 1982.

23. Warringon EK, James $M$, Kinsbourne $M$. Drawing disability in relation to laterality of cerebral lesion. Brain 1966; 89: 53-82.

24. Bay E. Aphasia and non-verbal disorders of language. Brain 1962; 85: 411-426. 